\title{
Exploring the impact of involving fathers in the treatment of their children: A study using Interpretative Phenomenological Analysis (IPA)
}

\author{
Anna Elisabeth Iversen, Barbara Hoff Esbjørn, Elisabeth Christensen \& Nina Schultz Hansen
}

\begin{abstract}
Although fathers have been shown to contribute uniquely to the development of psychopathology in children, they continue to be ignored in research and clinical work. Knowledge about the impact of involving fathers in their child's treatment - for the child, couple and the family as a whole - is still sparse. The aim of this study was to explore parents' experiences of having fathers involved in the treatment of their child. Parents, whose children had received cognitive behavioural therapy for an anxiety disorder, were interviewed about this topic. The participating parents had all been involved in the treatment of their child. Interpretative phenomenological analysis (IPA) was used to analyze the data in this study. Three higher order themes and 11 subthemes emerged from the six interview accounts. The three higher order themes were as follows: Strengthening the family system, empowerment of parents, and impact on partner relationship. Results indicated that parents' experiences of the involvement of fathers to be beneficial not only on the child's treatment but also on other aspects of family life. The parents reported that the family as a whole benefitted from the treatment and that the relationship between the parents was strengthened. A model was created to conceptualize these results.
\end{abstract}

Keywords: childhood anxiety; family; father involvement; interpretative phenomenological analysis; treatment

Please cite this article as:

Iversen, A.E., Esbjørn, B.H., Christensen, E. \& Hansen, N.S. (2012). Exploring the impact of involving fathers in the treatment of their children: A study using Interpretative Phenomenological Analysis (IPA). Qualitative Studies, 3(1): 22-39.

\section{Introduction}

'Are we continuing to neglect fathers?' is the title of an editorial by A. Vetere (2004). The answer to the question is that they may not be neglected, but that they continue to be underrepresented. The editorial therefore encourages more writing about fathers and their role in the family. Surveys among clinicians confirm the same trend in clinical practice - that fathers participate less in treatment of their children than mothers do (e.g. Lazar, Sagi \& Fraser, 1991; Singh, 2003; Duhig, Phares \& Birkeland, 2002). Furthermore our understanding of the parents' experiences of involving fathers in the treatment of their children is very limited. However, as pointed out by Phares and colleagues (2006), it is not always clear whether this is due to the fathers refusing to participate, or if it is due to clinicians' practice of not including fathers in treatment. A detailed understanding of the mothers' and fathers' experiences of having fathers participate in treatments of the children may guide clinicians when deciding if fathers should be invited to participate in their child's treatment or not.

A review of the clinical child and family research published between 1984 and 1991, found that fathers were also clearly underrepresented in child and family research that focused on clinical issues (Phares \& Compas, 1992). In an update review 13 years later, they concluded that the situation had not changed much, and that fathers continue to be underrepresented in research on fathers and developmental psychopathology (Phares, Fields, Kamboukos \& Lopez, 2005). 
Zimmerman and colleagues reviewed five journals that focused on child and adolescent development and concluded that the same is true for the field of normal development, namely that fathers are clearly underrepresented (Zimmerman, Salem \& Notaro, 2000). However, although fathers have been neglected in research on child psychopathology as well as in clinical practice, they do have a unique influence on children's normal (e.g. Biller \& Lopez-Kimptom, 1997; Lamb, 1997; Pleck, 1997; Sarkadi, Kristiansson, Oberklaid \& Bremberg, 2008) as well as abnormal development (e.g. Connell \& Goodmann, 2002; Videon, 2005).

Furthermore, reviews of father involvement in parent training of disruptive children have found that inclusion of fathers in treatment was associated with improved treatment outcome at follow-up (Bagner \& Eyberg, 2003; Lundahl, Tollefson, Risser \& Lovejoy, 2008). Treatment programmes involving fathers will have the advantage over treatments only involving mothers, that both parents receive training in parenting behaviours that will increase positive behaviour towards the child as opposed to programs involving only the mother, who must then explain the parenting principals to the father. These findings indicate the importance of investigating the unique contribution of father involvement further, and beyond the area of children with disruptive disorders. Whether these findings extend to children with internalizing disorders, e.g. anxiety disorders, is largely unexplored. Furthermore the positive effect of involving fathers may potentially rise as a result of two committed parents working together in treatment, irrespective of the gender of the parents; however, research has focussed mainly on heterosexual two-parent families, as these are more common and numerous questions regarding the role of fathers are yet unanswered.

What is known is that fathers play an important role in the maintenance of childhood anxiety disorders. Fathers of anxious children have been found to exhibit more controlling and less autonomy granting behaviour than fathers of non-anxious children (Bögels, Bamelis \& Bruggen, 2008; Greco \& Morris, 2002). As anxiety disorders are among the most common psychiatric disorders in childhood (Cartwright-Hatton, McNicol \& Doubleday, 2006; Costello, Mustillo, Erkanli et al., 2003), studies of the value of including fathers in treatment of anxious children are also warranted. Evidence indicates that cognitive behavioural therapy (CBT) is an effective treatment, both when delivered to the child individually and when involving the parents of the child (Creswell \& Cartwright-Hatton, 2007). Nevertheless, most of the studies involving parents in the treatment of the anxious child involve only the mother. In contrast to the literature on externalizing behaviour, fathers have in this line of research been largely neglected.

When studying the role of fathers in relation to treatment, research has examined both direct and indirect effects. One indirect effect of the fathers' role in relation to treatment is the personal characteristics of the father. One such factor is paternal anxiety, which has been found to make a unique contribution to treatment outcome, as elevated levels of paternal anxiety has been linked to poorer treatment outcome (Liber, van Widenfelt, Goedhart et al., 2008; Rapee, 2000). Moreover, paternal somatisation (Crawford \& Manassis, 2001) and rejecting behaviours by fathers (Liber et al., 2008) have also been found to predict poorer treatment outcomes in anxious children. This is important, as it is widely known that anxious children are more likely to have anxious parents (Last, Hersen, Kazdin et al., 1991; Murray, Creswell \& Cooper, 2009). In addition to dealing with their own anxiety, these fathers may also be affected in terms of how they help their own children overcome anxiety. As pointed out by Bögels \& Phares (2008) fathers may play a different role compared to mothers, as fathers are often the ones who encourage the child to explore the external world, a behaviour that may be compromised if the father has anxiety himself (Bögels \& Phares, 2008). Another way, in which the father may play 
an indirect role on the children, is when the mother's rearing behaviour is affected by the father's emotional well-being and behaviours. In fact, Bögels and colleagues found that mothers are more negative towards their anxious children, if their partners suffer from anxiety. This may be due to the fact that paternal anxiety makes mothers more insecure as caregivers. The anxious fathers are also reported to be less supportive of their partners than non-anxious fathers in a control group (Bögels \& Phares, 2008). This may in turn affect the mothers' parenting ability, as mothers who feel supported by their partner show an improved interaction with their child (Bögels \& Phares, 2008; Bögels \& Brechman-Toussaint, 2006). McHale \& Rasmussen (1998) also found that lack of partner support is a strong predictor for child anxiety in young children.

Given the unique impact fathers have on the maintenance of children's anxiety disorders as well as on treatment outcome, it is vital that fathers receive more attention in intervention efforts targeting internalizing disorders, and that the impact of mothers and fathers is not assumed to be equivalent. However, in many of the existing studies, fathers either are not involved, or paternal effects are not studied separately. Therefore, the impact of including fathers is to a large extent unexplored.

The changing roles of fathers within families as well as changing notions of masculinity in the past few decades also underscore the importance of exploring the impact of involving fathers in the treatment of their children. Some argue that fatherhood and fathers' role in the family is not as straightforward and unproblematic to define as it perhaps once was (e.g. Yarwood, 2011; Finn \& Henwood, 2009). In recent years the concept of the "new father" has emerged, and the idea of the modern father as a caring, nurturing and emotionally involved co-parent involved in house work and child care has been an issue of some debate (Brandth \& Kvande, 1998; Finn \& Henwood, 2009; Yarwood, 2011). Although the concept of the traditional breadwinning, perhaps more distant, father continues to be a dominant construct, some studies point out that the role of the father within the family is indeed changing, as are fathering identities, towards a more actively involved, caring co-parent model (e.g. Finn \& Henwood, 2009). The changing role of fathers also implies that the boundaries between mothers' and fathers' gendered roles in the family are becoming more diffuse, as fatherhood is beginning to include some traditionally maternal qualities (e.g. caring for children; Brandth \& Kvande, 1998; Finn \& Henwood, 2009; Yaewood, 2011). This move towards 'new', increasingly involved fathers, who share responsibilities with mothers clearly emphasizes the need for further investigating the impact of involving fathers in the treatment of their children.

This study attempts to explore in detail parents' experiences of involving fathers in the treatment of their children. In-depth interviews with parents of anxious children are carried out in order to provide insights into their perspectives on this topic. As pointed out by Richardson (1996), qualitative research is particularly appropriate in cases where the topic of study is characterized by complexity, ambiguity and lack of prior theory and research. This last point certainly applies for this topic, and is also the reason why a qualitative approach was chosen for this study.

\section{Method}

\section{Methodology}

Interpretative phenomenological analysis (IPA; e.g. Smith, 1996; Smith, Jarman \& Osborn, 1999; Smith \& Osborn, 2003) was used to analyze the data in this study. IPA was developed for use in psychological research (Langdridge, 2004), and shares a number of similarities with grounded theory (Glaser \& Strauss, 1967) in that they both put emphasis on the experience and meanings 
of the participants (Langdrigde, 2004; 2007). However, IPA derives from the phenomenological tradition, and the focus of research is thus on investigating topics or objects as they are represented in and perceived by the participant. Thus, the method is concerned with the personal accounts and perceptions of a phenomenon. IPA does not attempt to create an objective account of an object or event (Smith \& Osborn, 2003), but aims to explore the participant's personal perception of a phenomenon. Another premise of IPA is that the research exercise is a dynamic process, as the researcher makes use of his own conceptions when trying to make sense of and interpret the other person's accounts (Smith, Flowers \& Osborn, 1997). Research questions in IPA projects are usually framed broadly and openly, and there is no attempt to test a predetermined hypothesis of the researcher. Instead 'the aim is to explore, flexibly and in detail, an area of concern' (Smith \& Osborn, 2003, p. 53). As the focus in the present study was exploring parents' perceptions, that is their phenomenological experience, of involving fathers in treatment, it was considered appropriate to make use of IPA.

\section{Participants and Recruitment}

The sample consisted of parents whose children had received cognitive behavioural therapy for an anxiety disorder. The participating parents had all been involved in the treatment of their child. Families, who had commenced and terminated treatment in the period January 2007 until April 2008, where both parents had attended the treatment, were invited to participate in the current study. An information letter was sent to them, in which the aim and procedures of the study were outlined. They were also informed that a decline of participation would have no effect on their future contact with the University Clinic, where they had received the treatment. The parents were instructed to return the consent form if they were interested in participating. The families were subsequently contacted by telephone in order to make an appointment for the interview.

Ten families returned the consent form. In two of these cases it turned out to be impossible to find convenient times for the interviews. Thus, eight families ended up participating in the study, two of which took part in the piloting of the interview guide. The six remaining families constituted the sample for the current study. In one of these families, it was only the father who participated, as the parents were in the process of being separated. In another family, the child's stepmother participated with the father, as she had lived with the child most of his life. In the remaining families, both parents took part in the interview. These were all cohabiting biological parents. Mothers and fathers had to take time off work in order to participate in the treatment. This was primarily paid for by themselves. Only one of the participants could take the required time off work without having to compensate. All participants were middle-class, caucasian Danes.

\section{The Intervention}

The treatment took place at a University Clinic, which provides treatment free of charge. All families had contacted the clinic on their own initiative and participated on a voluntary basis in the treatment. Participation of both parents was strongly encouraged, also in families where the parents were separated. All families received case formulation based cognitive behavioural therapy (CBT) following the standard procedure in this clinical setting. The treatment consisted of individual CBT sessions for the child in combination with parent sessions without participation of the child. The treatment started and ended with a family session where the child and the parents took part. 
The child and parent sessions focused on minimizing anxious behaviour in the child. The parent sessions were also used to address family dynamics that were maintaining the anxious behaviour in the child, e.g. overcontrolling/intrusive behaviour of the parents. Parents were also encouraged to bring other topics to the sessions if they experienced these as relevant for the well being of the child, e.g. how to encourage the child to turn to both parents when distressed.

\section{Data Collection}

A semi-structured interview guide was created and consisted of a range of open ended questions about the parents' experiences with having the father involved. The interview questions focused on the period before the treatment commenced, during treatment and after the treatment, at each time period focusing on the parents' reflections about having the father involved, and what it would have been like without the father's involvement. The interviews focused on positive and negative aspects of the fathers' involvement. The interview guide was complemented with structured questions on demographic data and information about the practicalities involved in terms of both parents coming to treatment. The initial interview guide was tested on two families, and subsequently adjusted accordingly. The data from the two pilot interviews were not used in the subsequent analyses, because the questions differed somewhat from the main sample.

The interview was administered to each set of parents at the same time. The duration of the interviews was between 23 and 55 minutes, with an average interview lasting 42 minutes. The shortest interview was with the parent who participated alone. All interviews were audio taped and transcribed verbatim. Audio records were deleted once the written records had been created. The confidentiality of the participants was secured by changing all names (person and places) in the written records. The written records were stored according to Danish regulations on storage of research data.

The interviews were conducted by two experienced clinicians who had not been involved the treatment of the families who participated. Because both interviewers were female, great care was taken to communicate to the fathers a genuine interest in their contribution. The mothers were also encouraged to consider the father's role in the treatment.

\section{Data analysis}

The analysis was carried out by the first three authors of the article. The coders had not been involved in the treatment or interviewing of the parents. IPA was used to analyze the data (e.g. Smith et al., 1999). The first step of the analysis involved a detailed reading and re-reading of the transcripts while initial thoughts and comments were recorded in writing on each individual transcript. In order to ensure trustworthiness regarding the findings, this process was carried out separately by the three coders. Subsequently the coders cross-checked their written comments with the two other coders. This triangulation of the analyses was employed in order to increase reliability and validity regarding the identified topics. Only topics on which the coders reached consensus were included in the following step. On the basis of this agreement, lists of comments were made for each transcript. The second step involved rereading the transcripts while extracting the salient topics. These were grouped thematically producing a list of themes for each transcript. This step was followed by a process of comparing themes across the different transcripts, attempting to make thematic connections between them. Subsequently these themes were clustered and higher order themes emerged, which reflected each cluster of subthemes. A master table was generated, listing higher order and subthemes. 
Consensus agreement was used during all steps of the process in order to increase internal validity.

Also, great care was taken by the coders to pay attention to positive and negative aspects in the parents' accounts, in order to minimize the influence of possible biases and preconceptions held by the coders regarding the importance of the fathers' involvement in the treatment. Positive aspects included all types of statements involving a positive evaluation of the topic in question, e.g. "This project would never have succeeded as well as it did had I not been there". Whereas negative aspects involved all types of negative evaluations of the topic in question, e.g." I was somewhat sceptical, because... well I am always sceptical about this type of treatment."

\section{Findings}

Three higher order themes and eleven subthemes emerged from the six interview accounts. The three higher order themes were as follows: Strengthening the family system, empowerment of parents, and impact on partner relationship. Each of these themes includes a number of subthemes, which are listed in Table 1.

\begin{tabular}{|c|c|}
\hline Higher order themes & Subthemes \\
\hline 1. Strengthening the family system & $\begin{array}{l}\text { a. Improved father-child relationship. } \\
\text { b. Increased sense of being united in the } \\
\text { family. } \\
\text { c. Preventing mothers from having } \\
\text { responsibility for information transfer. } \\
\text { d. Preventing isolation / detachment of } \\
\text { the father. }\end{array}$ \\
\hline 2. Empowerment of parents & $\begin{array}{l}\text { a. Unified as parents } \\
\text { b. Increased parental competence } \\
\text { c. Congruent views on child's difficulties } \\
\text { d. Supporting each other }\end{array}$ \\
\hline 3. Impact on partner relationship & $\begin{array}{l}\text { a. Equality between parents } \\
\text { b. Improved communication } \\
\text { c. Improved understanding for each } \\
\text { other }\end{array}$ \\
\hline
\end{tabular}

Table 1. List of higher order and subthemes

Strengthening the family system

This super-ordinate theme emerged from the participants' descriptions of a range of aspects, which they experienced as having a positive impact on the family system as a whole. Fathers as well as mothers described that the relationship between the father and the child improved. As one mother expressed it, 'Father and son have found each other.' The father added: 'Yes, at that point I was forced to focus on his everyday life and I became more attentive to how he was communicating at home, and how he reacted. In that way I was... I was put in the position that I had to get involved in his everyday life... I had to pay more attention to various things. And that was a good thing, because I became more aware of what was going on in his everyday life, how he was doing, and whether it had been a good or a bad day.'

Some parents reacted with surprise when told prior to treatment that both of them were expected to participate in the treatment of their child. As one father expressed it: 'I thought it 
was strange that we had to spend two people's time on talking about myself or about us, because it was X [the child] that was the issue.' And for some of the families it was difficult to find the time for both parents to participate in the treatment, which by some of the participants was perceived as a disadvantage: '...it takes two hours to get from where you are [work] until you're back again, and that implies that he [the father] can't leave the office early that day. That can be a disadvantage. I just don't think we thought about it that way, because we were both ready to sacrifice a great deal in order to make this work.' Although the families invested substantial time and energy in participating, there appeared to be a consensus that the time is well invested: 'You experience that the more time you spend on your child, the more you get in return.'

Throughout the interviews, it also became clear that the parents not only experienced an improved relationship between the father and the anxious child, but that there was a secondary effect which went beyond their dyad: 'I was positively surprised, and it turned out well. Today I get along better with my son than I've ever done before, also with my eldest son.'

The participants also described how the treatment contributed to a sense of family unity. In some of the families this feeling of unity was a product of the family being involved in a shared project: 'I think that it kind of makes the family stronger that we're all involved in it (...) because it is a shared task. If everybody is involved in it, then it is a shared task. If somebody is left out, then they wouldn't quite feel like they were a part of the task.' In other families the sense of unity developed because the father became more involved in the family and the family life than he was prior to treatment: 'I think it has paid off that Dad has participated and has been so involved in what was going on, because before we got help and X was feeling that way, I felt that I pretty much was left on my own with it. But that was because Dad didn't get a say regarding $X$. The fact that he has been able to participate here, I feel has brought together our family, because we have been united in the process.'

In some of the families there even appeared to be a development from dyads to a triad. The participants explained how they expected treatment without involvement of the father to strengthen the mother child dyad even more than was already the case, while the father-child relationship potentially would weaken. In general, the treatment seemed to contribute to a clarification of the father's role in the family. One father expressed how he has become a part of the family after the treatment: 'I've been given my family, I am in my family, I have kept my family... I have become a part of it, let me put it that way. That is probably the best thing... I've become a part of my family.'

Another subtheme which clearly emerged from the material was how parents experienced it as an advantage that both parents knew what the treatment was all about, and that they therefore were equally competent to deal with problems or conflict situations when they arise. Additionally, the participants experienced it as an advantage that one parent did not have the responsibility for making sure that the other parent was informed about the content of the sessions. One mother described how this scenario would put a bigger pressure on her as a mother, and give her more responsibility than the parent who was absent from the sessions. The fact that both parents participated, and therefore received the same information, also seemed to prevent disagreements about how to solve conflicts with the child. One participant described how treatment without involvement of the father could magnify conflicts between them as parents, as the father would not listen to her in the same way as he listened to the therapists, or that he would question her accounts of the sessions: 'I liked the fact that we got the same 
information about what to do, because if I had to communicate it all to you at home, I don't think you would have listened in the same way (...) and we have also been able to discuss some of the things we disagreed on, and to have other people say "this is how it is", because we have disagreed a lot along the way, especially before we came here, about how to deal with him.'

The participation of both parents was perceived as essential, especially in terms of preventing the father being detached or left out from the rest of the family. As one father described it: 'Then mother and daughter would have had that in common. They would have had this thing together, and I would have been left out, and it would have been hard relating to X's development. I guess. In terms of the father-daughter relationship, it would maybe have created a larger distance in the long term, and from a selfish point of view it would have been a sad experience to look at it all from the outside, or not being the one involved in the process and not having the full grasp of it.'

\section{Empowerment of parents}

This super-ordinate theme also emerged clearly from the interview accounts. Fathers and mothers seemed to agree that by participating in the child's treatment, they obtained a new common ground, or platform from which to develop as parents. And by participating together, they went through a joint learning process as parents, where they started out at the same place, gained the same knowledge as well as same problem-solving tools. They also expressed that they experienced feeling more unified as parents, and that they after the treatment have become more interested in understanding each other. The parents also expressed that they feel more competent as parents, both in terms of how to cope with the child with the anxiety disorder, but also in terms of parenting in general.

Another aspect, which they experienced as an advantage of participating together, is that they by the end of treatment had more congruent views on the child's difficulties, and how to deal with them. When asked what it would have been like, had the father not been involved in the treatment, one mother explains: "Then I really think it would have been like "Oh no, now she is seeing ghosts again" if I was the only one who had seen the warning signs, that were... it would become a matter of conflict, really, whether or not he was about to go down that road again. Because we both have the same information we don't have to discuss whether it's true or not.'

There was also a consensus that being two in the process facilitated the parents' support of each other, and that it put them at ease to know they are two to intervene with the child. This also enables more flexible problem solving, as both parents are trained to deal with potential difficulties. One parent described it as follows: 'One advantage is that both of us have received information about how to deal with him differently at home, and that we've been able to help each other and to support each other in the new way of communicating with him.'

\section{Impact on Partner Relationship}

Another aspect, which the participants drew attention to, is the fact that the participation of the father contributes to equality in the parents' relationship. They experience the parenting task as more equally shared between them, and believe that the absence of the father in the treatment would reinforce the asymmetry between the parents, as the mother would continue to take a greater responsibility for the children's anxiety. One of the mothers described it as follows: 'Now he is also a part of the family, now he participates in the decision making about the kids and all that. It used to be only me who took care of those things.' The participants also experience that the participation of both parents has improved the communication between 
them as partners, as well as in the family as a whole. They describe a more open dialogue as well as increased reflections about their parenting styles. The following citation from one of the mothers illustrates this point: 'It [the therapy] has opened up for some dialogue between the father and I about this, or about the way we have organized our lives.' This mother's partner expressed that 'the most important thing... was the participation itself, that we opened up for our thoughts about how we raise our children, and that we both need to raise them.'

The participants also experience a better understanding of each other's views on the child, as well as acceptance of their differences. They also describe having achieved more respect for each other's views, in turn minimizing conflicts, for example about how to deal with the child. One father described it as follows: 'In terms of ourselves, it gave us a good understanding of the ways in which we can understand things differently and interpret things differently and without really having thought about the other person (...) I think that it gave a good understanding of our differences, so you can say... not that it turned into couples therapy, but it was an eye opener in the sense that you take so much for granted and base it on your own perceptions or standpoint.'

\section{Discussion}

Rationale for involving fathers

Throughout the last couple of decades, a variety of paternal behaviours and personality characteristics have been shown to have an influence on the development of psychopathology in children, both as risk and protective factors (Bögels \& Phares, 2008; Connell \& Goodmann, 2002; Lamb, 1997; Sarkadi et al., 2008). However, documented knowledge is still lacking about the effect of involving fathers in treatment of children with anxiety disorders. Most child and adolescent clinicians have experienced the benefits of involving both parents in children's treatment. This study reiterates this practice. The results indicate that the parents experience that involving mothers as well as fathers in the treatment had an overall positive effect on the child. However, the benefits went beyond that, as the families also experienced positive effects on other aspects of family life. This is in accordance with findings from family systems literature, which highlights that the members of a family exert a continuous and reciprocal influence on each other (Cox \& Paley, 1997; Hughes \& Gullone, 2008). In an attempt to illustrate our findings, a model was created (see figure 1 below). 
Expected relationships: Father not involved

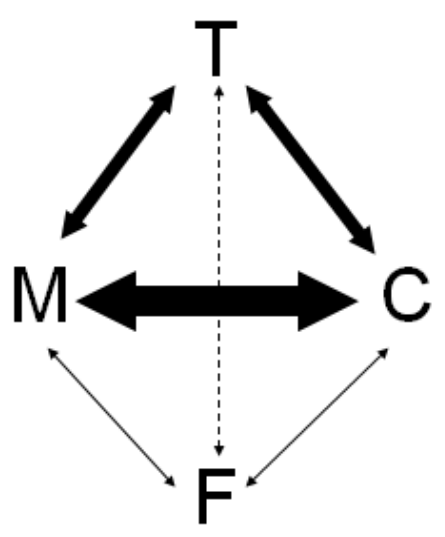

Experienced relationships: Father involved

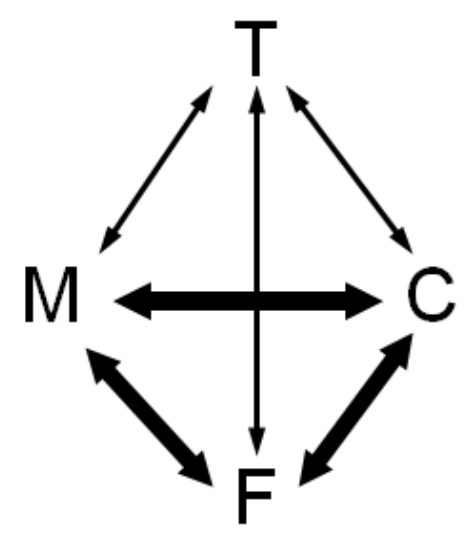

M: mother; F: father; T: therapist; C: child

The figure illustrates how the parents expected the relationships between therapist, child, mother and father to be like, had the father not been involved in treatment, versus how they actually experienced these relationships, based on having the father involved. The model is hypothetical and should be investigated in further studies before firm conclusions can be drawn regarding its validity.

In her discussion about why fathers are underrepresented in research on child and family functioning, Phares proposes several explanations for why fathers are neglected in treatment efforts. One of her explanations is that clinicians and researchers alike rely on theoretical frameworks which fail to take account of the fathers' contribution to their children's development. Other explanations put forward by Phares is the assumption that fathers are not involved in their children's lives to the same extent as the mothers, or that fathers are unable or unwilling to participate in intervention efforts (Phares, 1996). However, the findings from this study indicate otherwise, namely that fathers are both able and willing to participate in the treatment of their child when they are encouraged to do so. This is corroborated by another study, where fathers' attendance in their child's treatment was found not to be related to work hours or family rolls but instead to the fathers' relationship with their own fathers (Walters, Tasker, \& Bichard, 2001).

Studies of families where one of the members suffer from internalizing disorders report greater levels of family dysfunction than families with no disorders, including less confidence in problem solving and conflicts between parents regarding disagreement over child rearing (Hughes \& Gullone, 2008). According to family systems theory, optimal functioning in families requires that the family members are able to access resources from the larger family (Cox \& Paley, 1997). In treatment where only mothers and child are involved, they may not be able to access resources from the fathers, as he will represent the family's function as it was prior to treatment. As families are held together by rules and relations that pull towards equilibrium in the families, changes in the system create new vulnerabilities. For the change to become 
adaptive and stable, changes must occur at all levels of the family system. When fathers participate in the therapy, they may be empowered to enter the family in new ways at the different levels (father-child and spouse-relation) thereby increasing the likelihood that a new family structure may be created, applying more adaptive family rules and relations than prior to the treatment (Cox \& Paley, 1997). This is in line with what was found in this study, as the participants see it as a necessity that the father takes part in treatment, as it enhances the quality of the father-child relationship as well as the father-mother relationship.

Direct and indirect effects of involving fathers in treatment

As suggested by Bögels \& Phares (2008), fathers of anxious children may contribute to their child's development in direct and indirect ways. The direct impact may occur in the domain of play activities, attachment and involvement in the child. The indirect influence may occur through the fathers' impact on the mothers. When the father is supportive, the mother has more energy to care for her child. This is in line with the findings from the present study. When fathers were involved in treatment, they reported that they experienced a change in the fatherchild relationship as well as in the relationship between the parents. Although we did not explicitly explore how this change in father-child relationships manifested itself, one could expect an improved relationship to involve more play and a greater involvement in the child's everyday life. Moreover, the finding that the parents experienced the involvement of the fathers to create a common ground from which they could help the child is corroborated by research showing that similarities in rearing behaviour between parents is associated with lower parenting stress for mothers (Harvey, 2000).

In prior research, fathers of anxiety-disordered children have been shown to be less supportive toward their partners (Bögels \& Phares, 2008). This reiterates the necessity of enhancing also the relationship between mothers and fathers in order to enable them help their child overcome its difficulties. This finding may also explain why the mothers in the present study were so relieved by the achieved improvements in the partner relationship. Support from the partner has also been found to enhance the quality of the mother-child relationship (Bögels \& Brechman-Toussaint, 2006), whereas the lack of a common ground for parenting, with parents who put each other down in the presence of the child, are found to maintain child anxiety over time (Katz \& Low, 2004).

The inclusion of both parents also enables clinicians to address marital and coparenting issues that may affect the child's anxiety. Coplin \& Houts (1991) found that maritally distressed couples may have difficulty maintaining and generalizing skills learnt in parent training for oppositional child behaviour. According to Lee \& Hunsley (2006), parenting interventions are strengthened when the coparental relationship is attended to. Coparenting is defined as the ways that parents work together in their roles as parents and includes the degree of support between the parents, the extent of childrearing disagreement, the division of childcare and household duties and responsibilities, as well as the alliance between the parents (Feinberg, 2002). Lee \& Hunsley are referring to psychological services in general, when they encourage more attention to coparenting. However, to the best of our knowledge, their hypothesis has not been studied in interventions with anxious children. A recent review of the family systems literature of families with internalizing disorders, reported that these families function poorly overall, but also specifically regarding marital relations, parenting styles and parental attachment (Hughes \& Gullone, 2008). These findings stress the need for intervention at different levels in the family, including the marital relations and coparenting, if psychopathology is to be prevented. Based on the interviews from this study there is some 
indication that this also applies to families with anxious children, and that it was useful for the parents to address marital and coparenting issues.

As pointed out by Bögels \& Phares (2008), involvement of all fathers - anxious, divorced and those who find it hard to get off work - is necessary if we are to understand the true contribution of fathers on the development, maintenance and treatment of childhood anxiety. However, our results indicate that the way in which the fathers are involved in their child's development may play an important role. Phares and colleagues also suggested that therapists may consider using mothers to convey information about the treatment to the fathers (Phares et. al., 2006). This suggestion is not supported by the findings in this study, which indicate that if mothers attend the sessions by themselves and are left to convey information about involvement of the father to him at home, this may increase the level of conflict between the parents. The mothers in the present study expressed great relief that they did not have to take on this mediating role, but instead could engage in a more equal partner relationship, as illustrated in figure 1 . This is not surprising, when taking into account that mothers still have more overall responsibilities in terms of childcare compared to fathers (Craig, 2006; Leslie, Anderson \& Branson, 1991; Renk et al., 2003).

It is important to acknowledge that some, if not all, of the above mentioned effects of involving fathers in treatment of their children, may not be gender-specific. Some of these effects may arise as a result of two committed parents working together in treatment, irrespective of the gender of the parents. Thus, similar findings might have been found if the two parents constituted a gay or lesbian couple. In a recent review of studies comparing heterosexual twoparent families with homosexual two-parent families and single-parent families on a number of parenting measures, Biblarz and Stacey (2010) found no evidence of gender-exclusive parenting abilities. Research indicates that the strengths and abilities typically associated with heterosexual two-parent families are found to the same degree in families headed by two women and presumably, although comparable research on this area has not yet been generated, in families headed by two men (Biblarz \& Stacey, 2010).

As this study only included families, who were heterosexual, conclusions cannot be drawn as to whether the findings also apply to homosexual two-parent families or other family constellations (e.g. intergenerational families). Further research would be required in order to establish whether the findings in this study are specific to involving fathers from heterosexual families in children's treatment or if they can be generalized to other family forms.

\section{Limitations}

The findings from the current study need to be considered in light of the limited sample size, and the fact there is no follow-up data. In his book about qualitative research interviewing, Steinar Kvale suggests that one ought to interview as many persons as necessary in order to find out what you need to know (Kvale, 1997). We do not believe that the current topic of study has been exhausted with this small scale study. On the contrary, we urge further study of father involvement with larger sample sizes applying a quantitative design, or more heterogenic samples (e.g. other types of two-parent family involvement) using a qualitative design. In this study fathers and mothers primarily see advantages in involving fathers in treatment. However, the findings may have looked different, had we also included families in the study, where only one parent participated in the treatment. Also, it is not clear whether those parents who chose not to participate in this study had a different experience in terms of involving the father. Those who participated in this study all expressed an overall satisfaction with the treatment, and in 
general experienced a reduction in the child's symptoms. It would strengthen the study significantly if parents who failed to experience a noticeable effect of the treatment took part in this study. Interviews with these families could help generate richer data about the effect of involving the father. Last, but not least, it would be ideal to also interview the children about their perceptions of having the father involved in the treatment. This was however beyond the scope of this study. Further research is needed before firm conclusions can be drawn on this topic, and before we know whether these findings can be generalized to this clinical group.

It should be noted, however, that generalization is conceptualized rather differently within qualitative and quantitative research respectively. Within the field of qualitative research there is a growing tendency to emphasize the contextuality and heterogeneity of local knowledge over the universal generalization of results. Kvale (1997) mentions three goals of generalization within qualitative research: what is present, what is possible, and what could be. The study of what is present is the attempt to capture the typical and usual, whereas the study of what is possible highlights ends of the spectrum of possibility - e.g. to generalize what will be typical and usual in the future, but isn't quite yet. Finally the study of what could be is the examination of situations thought to be ideal or exceptional. In this respect, research, besides describing the present and foreseeing the immediate future, can partake in reshaping/transforming the culture of a certain practice.

Implications and future research

Because of the limited sample size of this study, the implications for clinical practice are limited at this point. However, based on these parents' accounts, there is some indication for encouraging fathers to take part in treatment alongside with the mother. For many clinicians who work with children, it is common sense to involve both parents in the intervention. However, our clinical practice also needs to be guided by evidence based practice. Another question to arise from this study is whether co-parenting should be addressed more systematically in clinical practice, which has been argued by Lee \& Hunsley (2006). The parents who took part in this study experienced benefits in terms of coparenting, even though coparenting was not explicitly on the agenda in this treatment setting. On that basis it is relevant to reconsider whether coparenting should become a more explicit part of the treatment in this setting, as well as others.

Further research is warranted, in order to test some of the hypotheses generated in this study as well as other areas of father involvement. A larger scale study would be especially useful, as a larger sample would strengthen the reliability of the data, and also increase the chances of including participants who were dissatisfied with the treatment, or whose children did not get better in spite of treatment. Another aspect which could shed more light on the effects of involving fathers is to investigate if there is an association between paternal involvement in therapy and direct effects on the child. Added benefits of father involvement, perhaps not surprisingly, have been found in other clinical groups (e.g. Bagner \& Eyberg, 2003; Coplin \& Houts, 1991; Webster-Stratton, 1985). One would expect the same to be true in families with anxious children. However, in addition to studying the obvious, whether there is a larger reduction in symptoms when the father is involved, it could be interesting to investigate if there are certain types of symptoms or behaviours that change when the father is involved in the treatment. 
The participants in this study were recruited from a clinic providing therapy for children with anxiety disorders. Evidently, the questions raised in this study are also worth studying in other clinical groups.

\section{Conclusion}

This study investigated parents' perceptions of having fathers involved in the treatment of children with an anxiety disorder. Although the results are preliminary, they indicate that involving fathers had beneficial effects not only on the child's treatment but also on the relationship between the parents. The parents reported that the family as a whole had benefitted from the treatment and that the relationships between the parents had become more equal, consequently making them better at supporting each other in helping the child overcome its difficulties.

\section{Acknowledgement}

We are very grateful to the parents who took the time to participate in this study. We also would like to express our gratitude to Helle Dittmann for interviewing the parents.

\section{References}

Bagner, D. M., \& Eyberg, S. M. (2003). Father involvement in parent training: When does it matter? Journal of Clinical Child and Adolescent Psychology, 32, 599-60.

Biblarz, T.J. \& Stacey, J. (2010). How Does the Gender of Parents Matter? Journal of Marriage and Family, 72, 3-22.

Biller, H. B., \& Lopez-Kimptom, J. (1997). The Father and the School-Aged Child. In M. E. Lamb (Ed.), The Role of the Father in Child Development (3rd Ed., pp. 143-161). New York: John Wiley \& Sons.

Bögels, S., Bamelis, L., \& van der Bruggen, C. (2008). Parental rearing as a function of parent's own, partner's, and child's anxiety status: Fathers make the difference. Cognition $\mathcal{E}$ Emotion, 22, $522-538$.

Bögels, S. M., \& Brechman-Toussaint, M. L. (2006). Family Issues in child anxiety: Attachment, family functioning, parental rearing and beliefs. Clinical Psychology Review, 26, 834-856.

Bögels, S., \& Phares, V. (2008). Fathers' Role in the Etiology, Prevention and Treatment of Child Anxiety: A Review and New Model. Clinical Psychology Review, 28, 539-558.

Brandth, B. \& Kvande, E. (1998). Masculinity and child care: the reconstruction of fathering. The Sociological Review, 46, 293-313.

Cartwright-Hatton, S., McNicol, K., \& Doubleday, E. (2006). Anxiety in a neglected population: Prevalence of anxiety disorders in pre-adolescent children. Clinical Psychology

Review, 26, 817-833.

Connell, A. M., \& Goodmann, S. H. (2002). The association between psychopathology in fathers versus mothers and children's internalizing and externalizing behaviour problems: A metaanalysis. Psychological Bulletin, 128, 746-773. 
Coplin, J. W., \& Houts, A. C. (1991). Father involvement in parent training for oppositional child behaviour: Progress or stagnation? Child and Family Behaviour Therapy, 13, 29-51.

Costello, E. J., Mustillo, S., Erkanli, A., Keeler, G., \& Angold, A. (2003). Prevalence and Development of Psychiatric Disorders in Childhood and Adolescence. Archives of General Psychiatry, 60, 837-844.

Cox, M. J., \& Payley, B. (1997). Families as Systems. Annual Review of Psychology, 48, 243-267.

Craig, L. (2006). Does Father Care Mean Father Share? A Comparison of How Mothers and Fathers in Intact Families Spend Time with Children. Gender \& Society, 20, 259-281.

Crawford, A. M., \& Manassis, K. (2001). Familial Predictors of Treatment Outcome in Childhood

Anxiety Disorders. Journal of the American Academy of Child and Adolescent Psychiatry, 40, 11821189.

Creswell, C., \& Cartwright-Hatton, S. (2007). Family Treatment of Child Anxiety: Outcomes, Limitations and Future Directions. Clinical Child and Family Psychology, 10, 232-252.

Duhig, A. M., Phares, V., \& Birkeland, R. W. (2002). Involvement of fathers in therapy: A survey of clinicians. Professional Psychology: Research \& Practice, 4, 389-395.

Feinberg, M.E. (2002). Coparenting and the transition to parenthood. A framework for prevention. Clinical Child and Family Psychology Review, 5, 173-175.

Finn, M. \& Henwood, K. (2009). Exploring masculinities within men's identificatory imaginings of first-time fatherhood. British Journal of Social Psychology, 48, 547-562.

Glaser, B. G., \& Strauss, A. L. (1967). Grounded theory techniques. New York: Sage

Greco, L. L. A. \& Morris, T. T. L. (2002). Paternal child-rearing style and child social anxiety: Investigation of child perceptions and actual father behaviour. Journal of Psychopathology and Behavioural Assessment, 24, 259-267.

Harvey, E. A. (2000). Parenting similarity and children with attention-deficit/hyperactivity disorder. Child and Family Behaviour Therapy, 22, 39-54.

Hughes, E. K., \& Gullone, E. (2008). Internalizing symptoms and disorders in families of adolescents: A Review of family systems literature. Clinical Psychology Review, 28, 92-117.

Katz, L. F., \& Low, S. M. (2004). Marital violence, co-parenting, and family level processes in relation to children's adjustment. Journal of Family Psychology, 18, 372-382.

Kvale, S. (1997). Interview. En introduktion til det kvalitative forskningsinterview. Copenhagen: Hans Reitzel.

Lamb, M. E. (Ed.). (1997). Fathers and child development: An introductory overview. In M. E. Lamb (Ed.), The role of the father in child development (3rd ed., pp. 1-18). New York: Wiley. 
Langdridge, D. (2004). Research methods and data analysis in psychology. Essex: Pearson Education Limited.

Langdridge, D. (2007). Phenomenological psychology. Theory, research and method. Essex: Pearson Education Limited.

Last, C. G., Hersen, M., Kazdin, A., Orvaschel, H., \& Perrin, S. (1991). Anxiety Disorders in Children and Their Families. Archives of General Psychiatry, 48, 928-934.

Lazar, A., Sagi, A., \& Fraser, M. W. (1991). Involving fathers in social services. Children \& Youth Services Review, 13, 287-300.

Lee, C. M. \& Hunsley, J. (2006). Addressing Coparenting in the Delivery of Psychological Services to Children. Cognitive and Behavioural Practice, 13, 53-61.

Leslie, L., Anderson, E. A. \& Branson, M. P. (1991). Responsibility for Children. The Role of Gender and Employment. Journal of Family Issues, 12, 197-210.

Liber, J. M., van Widenfelt, B. M., Goedhart, A. W., Utens, E. M. W. J., van der Leeden, A. J. M, Markus, M. T., \& Treffers, P. D. A. (2008). Parenting and Parental Anxiety and Depression as Predictors of Treatment Outcome for Childhood Anxiety Disorders: Has the Role of Fathers Been Underestimated? Journal of Clinical Child \& Adolescent Psychology, 37, 747-758.

Lundahl, B. W., Tollefson, D., Risser, H., \& Lovejoy, M. C. (2008). A Meta-Analysis of Father Involvement in Parent Training. Research on Social Work Practice, 18, 97-106.

McHale, J. P., \& Rasmussen, J. L. (1998). Coparental and group-level dynamics during infancy: Early family precursors of child and family functioning during preschool.

Development and Psychopathology, 10, 39-59.

Murray, L., Creswell, C., \& Cooper, P. J. (2009). The development of anxiety disorders in childhood: an integrative review. Psychological Medicine, 39, 1413-1423.

Pleck, J. H. (1997). Paternal Involvement: Levels, Sources, and Consequences. In M. E. Lamb (Ed.), The Role of the Father in Child Development (3rd Ed., pp. 66-103). New York: John Wiley \& Sons.

Phares, V. (1996). Conducting Nonsexist Research, Prevention, and Treatment with Fathers and Mothers: A Call for A Change. Psychology of Women Quarterly, 20, 55-77.

Phares, V., \& Compas, B. E. (1992). The role of fathers in child and adolescent psychopathology: Make room for daddy. Psychological Bulletin, 111, 387-412.

Phares, V., Fields, S. \& Binitie, I. (2006). Getting Fathers Involved in Child-Related Therapy. Cognitive and Behavioural Practice, 13, 42-52.

Phares, V., Fields, S. Kamboukos, D., \& Lopez, E. (2005). Still looking for poppa. American Psychologist, 60, 735-736. 
Rapee, R. M. (2000). Group Treatment of Children with Anxiety Disorders: Outcome and Predictors of Treatment Response. Australian Journal of Psychology, 52, 125-129.

Renk, K., Roberts, R., Roddenberry, A., Luick, M., Hillhouse, S., Meehan, C., et.al. (2003). Mothers, Fathers, Gender Role, and Time Parents Spend With Their Children. Sex Roles, 48, 305315.

Richardson, J. (1996). Handbook of qualitative research methods of psychology and the social sciences. Leicester: PBS Books.

Sarkadi, A., Kristiansson, R., Oberklaid, F., \& Bremberg, S. (2008). Fathers' Involvement and Children's Developmental Outcomes: A Systematic Review of Longitudinal Studies. Acta Pædiatrica, 97, 153-158.

Singh, I. (2003). Boys Will Be Boys: Fathers' Perspectives on ADHD Symptoms, Diagnosis, and Drug Treatment. Harvard Review of Psychiatry, 11, 308-316.

Smith, J. A. (1996). Beyond the divide between cognition and discourse: Using interpretative phenomenological analysis in health psychology. Psychology \& Health, 11, 261-271.

Smith, J. A., Flowers, P., \& Osborn, M. (1997). Interpretative phenomenological analysis and health psychology. In L. Yardley (ed.), Material Discourses and Health (pp. 68-91). London: Routledge.

Smith, J. A., Jarman, M., \& Osborn, M. (1999). Doing Interpretatitve phenomenological anlysis. In Murray, M. \& Chamberlain, K. (Eds.), Qualitative health psychology: theories and methods (pp. 218-240). London: Sage.

Smith, J. A. \& Osborn, M. (2003). Interpretative phenomenological analysis (pp. 51-80). In Smith, J. A. (Ed.), Qualitative Psychology: A Practical Guide to Research Methods. London: Sage.

Vetere, A. (2004). Editorial: Are we continuing to neglect fathers? Clinical Child Psychology and Psychiatry, 9, 323-326.

Videon, T. M. (2005). Parent-child relations and children's psychological well-being: Do dads matter? Journal of Family Issues, 26, 55-78.

Walters, J., Tasker, F., \& Bichard, S. (2001). 'Too busy?' Fathers' attendance for family appointments. Journal of Family Therapy, 23, 3-20.

Webster-Stratton (1985). The effects of father-involvement in parent training for conduct problem children. Journal of Child Psychology and Psychiatry, 26, 801-810.

Yarwood, A.G. (2011). The Pick and Mix of Fathering Identities. Fathering: A Journal of Theory, Research and Practice About Men as Fathers, 9, 150-168. 
Zimmermann, M. A., Salem, D. A., \& Notaro, P. C. (2000). Make room for Daddy II: The positive effects of fathers' role in adolescent development. In R. D. Taylor, \& M. C. Wang (Eds.), Resilience across contexts (pp. 233-253). Mahwah, NJ: Lawrence Erlbaum.

\section{Authors}

Anna Elisabeth Iversen (corresponding author) is a clinical psychologist working at Child and Adolescent Psychiatric Centre Bispebjerg, Copenhagen. Email: Anna.Elisabeth.Iversen@regionh.dk. Barbara Hoff Esbjørn is an associate Professor at The Copenhagen Child Anxiety Project, University of Copenhagen, Department of Psychology. Elisabeth Christensen is a clinical psychologist working at a private clinic specialized in providing services for families with children with autism spectrum disorders. Nina Schultz Hansen is a master level psychology student at The University of Copenhagen and is currently attached to The Copenhagen Child Anxiety Project. 